\title{
The Dinaledi Intervention Program
}

\author{
T. Ncanywa \\ University of Limpopo, Turfloop Campus, South Africa \\ ncntho73@gmail.com, Thobeka.ncanywa@ul.ac.za
}

\begin{abstract}
The study seeks to examine the relationship between educational inputs, primarily the Dinaledi intervention program and schooling outcomes. The Dinaledi program is one of the government's intervention programs to redress the inequalities and provided education resources to the previously disadvantaged communities in South Africa. The study employed a pseudo panel analysis on the attempt to answer the question of interest. Considering the random effect regression, Dinaledi schools were less likely to increase dropout rate by $0.099 \%$ with reference to non-Dinaledi schools. The pseudo panel analysis indicated a positive and significant association of the Dinaledi schools to pass rates. Further extensions of the analysis were looking at the distribution of the Dinaledi program on racial and gender issues by using the DiNardoFortin-Lemieux (DFL) estimation. It can be concluded that schooling outcomes can be strongly influenced by the Dinaledi intervention program with females and Blacks becoming more responsive to dropping out than their counterparts. Looking at the nature of resources and support provided to Dinaledi schools, it is recommended that the entire schooling system adopt the model to eradicate the legacy of inequality and improve schooling outcomes.
\end{abstract}

Keywords: Dinaledi intervention, pseudo panel data analysis, dropout rates, random effects, DiNardo- FortinLemieux (DFL)

\section{Introduction}

Schooling outcomes such as dropout and pass rates are a major concern in education especially in developing countries today. Exit learners in the schooling system (matriculates) show persistent patterns of underachievement particularly in Mathematics and Science subjects. Poor performance in these subjects lead to shortages in the most important skills such as engineering and these shortages constrain economic growth and employment creation. The poor schooling outcomes might lead to learners failing to finish schooling or deprived a chance to meet the admission requirements in tertiary institutions. Although there is a welcomed development in issues like enrolment and participation of learners in the Sub-Saharan regions, the challenge remains on improving the quality of education and increasing the number of matriculates with powerful Mathematics and Science results. For example, secondary school enrolment in Northern Africa was around 45\%, 25\% in South Eastern Africa, 13\% in Central Africa and 100\% in South Africa (DoE, 2009). The matriculation pass rate gradually increased in South Africa from 58\% in 1994 to 65\% in 2013, however, South Africa came last in the Trends in International Mathematics and Science Study (TIMSS) (DoE, 2003; DoE, 2007; DBE, 2014). This implies that an increase in pass rates may be pulled down by the high failure rate in Mathematics and science.

Responding to the concern of improving schooling outcomes, an interesting approach to assist students succeed is to examine if intervention programs can influence schooling outcomes. Discovering intervention programs that may reduce dropout rates and increase pass rates would be beneficial not only for individual learners but also for the society as the whole. Intervention programs for improving schooling outcomes have been developed. In this article, existing literature is integrated with the research that examines the Dinaledi intervention program effects on schooling outcomes. The Dinaledi program is the South African government intervention program collaborating with businesses for the redress of the inequalities, which provided resources to disadvantaged Black communities. The program started in 2002 to provide schools with extra resources for Mathematics, Physical science and Life science, learners provided with textbooks and mathematics kits; schools provided with laboratories and projectors; and educators trained on content (OECD, 2008); (DoE, 2011). 
Studies on the Dinaledi intervention program are limited, for instance, there was an evaluation of the Dinaledi program which was done by the World Bank in the period 2005 to 2007 (DIME, 2008). However, studies of the effects of intervention programs indicated a positive relation to schooling outcomes (Boardman et al., 1977; Mutsalklisana, 2011). This study attempts to find an effective mechanism for narrowing gap in resources and improving quality, productivity and accountability in education adopting education production functions. In educational microeconomics, the education production function or frontier is an education process that transforms input indicators into outcomes (Hanushek, 1989; Hanushek, 1990; Behn, 2003). Education production functions in schools essentially aim to identify which education inputs such as government intervention programs, teacher qualifications, availability of teaching materials and teaching time, have an effect on schooling outcomes (Mancebon \& Molinero, 2000; Ray, 1991; Bhorat \& Oosthuizen, 2006; Glewwe, 2002). This study extends the understanding of the link between inputs and output for the education production function using parametric and non-parametric density/ regression techniques. Therefore, the study sought to examine the relationship between the Dinaledi intervention program and schooling outcomes. In addition, there is an examination of equity in racial and gender issues to discover how they relate to school performance. Section 2 provides literature review, section 3 analytical framework that includes data issues and empirical models. Section 4 deals with results and discussions, and section 5 concludes by providing a summary of the findings and recommendations.

\section{Literature Review}

Theoretical literature: This study adopts a production function approach for learning to understand the causal relationship between educational inputs and academic achievements (Glewwe \& Kremer, 2006). Due to lack of information on some characteristics of structural relationships of production functions such as learner and parent information, the structural model is not easily measured (Boardman et al., 1977). Therefore, a causal relationship, which is a reduced form equation in the following form, can be used:

$$
\boldsymbol{A}=f(\boldsymbol{S}, \boldsymbol{Q}, \boldsymbol{H})
$$

A is a scalar representing achievement which can be captured by standardized test scores, grade attainment or dropout rates. $\mathrm{S}$ is a vector of school characteristics usually captured by learner educator ratios, Dinaledi schools, location were the school operates (sector) and so on. Q represents learner characteristics usually captured by gender and race. $\mathrm{H}$ is a vector of household characteristics, which act as control for socioeconomic characteristics, and is represented by quintile category of schools in this study. The study attempts to measure $\boldsymbol{A}^{\prime}($.); which provides the total derivative of A with respect to each of the individual variables defined within vectors. According to Hanushek (1989), the production function approach which can be inputoutput or cost-quality approach is the most appropriate and useful approach in education studies. The production function for schools focuses on the relationship between school outcomes and measurable (observable) inputs into the educational process. Educational systems have no single defined production function, and no well-defined indicators of input and output (Hanushek, 1989). In most studies of the education production function, the measure of input and output is limited by the availability of data. Therefore, various educational outcomes can result from a variety of different combinations of inputs. Examples of output found the literature include academic performance; skills, attributes and values that favor workplace and social integration; communication and interpersonal skills, respect for the environment, physical fitness; and political, social and personal responsibility, grade repetition rates, or dropout rates (Hanushek, 1989; Ray, 1991; Giménez et al., 2006; Schwartz \& Stiefel, 2004; Thieme et al., 2011). This study measures output using the dropout rates. On the other hand, inputs which are also referred to as instructional expenditures can be grouped as school, educator; student and household characteristics(Hanushek, 1989; Borge \& Naper, 2006). In this paper, inputs include whether a school is a Dinaledi school or not, the grade 12 pass rates, gender, race, sector and quintile category of schools.

Empirical literature: Boardman and Murnane (1979) addressed the estimation of educational attainment using cross-sectional data, achievement measures at two points and panel data. They found that the panel analysis gave more nuanced results as it addressed the bias, although they assumed that there was no measurement error (Boardman \& Murnane, 1979). Boardman, Davis and Sanday (1977) estimated a reduced form achievement equation in a simultaneous equations model with maximum likelihood estimation. Their 
model examined the determinants of pupil achievement through verbal, non-verbal, reading and mathematical skills (Boardman et al., 1977). They found that both home and school characteristics are significant determinants of achievement; however, there are substantial differences in the average achievement of racial groups. In addition, males are better achievers but females are better readers, and pupils who attend white schools perform better than others. The World Bank evaluated the Dinaledi schools' performance in the South African National senior certificate examinations in Mathematics and Physical science (DIME, 2008). The study used matching and the difference in difference techniques to estimate the impact of the Dinaledi program in the period 2005 to 2007 and found that the program improved performance. Another study by Mutsalklisana, evaluated the effects of job training on immigrants in the United States (Mutsalklisana, 2011). The researcher used Random effects, Propensity Score Matching, quantile regressions and semi-parametric reweighting method to measure these effects. The results revealed the conditional effect of job training on average earnings of immigrants is less than that of natives at $7.7 \%$. The distribution analysis showed a positive effect on wages of immigrant workers over most of the wage distribution. The DiNardo-Fortin-Lemieux (DFL) counterfactual distributions indicated that the largest proportional impact of job training is at the upper part of the wage distribution for both natives and immigrants. On the attempt to answer the question of interest, the relationship between the Dinaledi intervention program and school outcomes, the pseudo panel analysis was adopted from Boardman et al. (1977) and Verbeek (2007). Further extensions of the analysis looked at the distribution of the Dinaledi program on gender issues; hence, the DFL was adopted from Johnston \& DiNardo (1997). Gender was investigated to find out if the province still had persistent gender gaps.

\section{Data and Method}

Data issues: The data used was obtained from the examination directorate of the Province of Eastern Cape Education in South Africa. A random sample of the Eastern Cape public schools with grade 12 examination results was selected with longitudinal data for the period 2008 to 2013. The data suffered some drawback within the context of estimating the education production function. For instance, the data was at school level and not at learner level and constrained the validity of the estimates derived. In addition, data lacked educator characteristics, direct learner, and parent information. This means that estimates suffered from the omitted variable bias, which could not be controlled for. The data also suffered selection bias, as it did not provide variables such as grade repetition rate. The study sought to address some of the biases by using different estimation techniques in the pseudo panels. For instance, according to Deaton (1985) and Verbeek (2007), pseudo panels are advantageous as they suffer less attrition and non-response, reduce biasing effects of measurement error, improve coverage and reduce endogeneity as the variables used are all aggregated at the cohort level. They are substantially larger in number of households and in the time, they span. There is also a reduction of the number of laborious computational problems associated with large micro data sets. However, its major limitation is not following the same individuals over time, so individual histories are not available for inclusion in the model, for constructing instruments or transferring the model to first differences. It is advantageous, however, to undertake the study as a guide for improving on future research of this sort with better quality data. The study serves as a benchmark for evaluating the possible effects of the redress in developing countries. The large sample of grade 12 offering schools and the estimation techniques added to the robustness of results and control for the aforementioned biases.

Table 1: Descriptive statistics: Eastern Cape dropout and pass rates, 2008 to 2013

\begin{tabular}{llllllll}
\hline & $\mathbf{2 0 0 8}$ & $\mathbf{2 0 0 9}$ & $\mathbf{2 0 1 0}$ & $\mathbf{2 0 1 1}$ & $\mathbf{2 0 1 2}$ & $\mathbf{2 0 1 3}$ & All \\
\hline $\begin{array}{l}\text { DROPOUT } \\
\text { MEAN }\end{array}$ & 0.633 & 0.495 & 0.838 & 0.609 & 1.159 & 0.697 & 0.739 \\
Standard Deviation & 1.309 & 0.986 & 1.499 & 1.503 & 2.890 & 1.823 & 1.789 \\
Min & 0 & 0 & 0 & 0 & 0 & 0 & 0 \\
Max & 16.117 & 11.486 & 13.99 & 16.788 & 16.789 & 16.789 & 16.789 \\
PASS RATE MEAN & 54.719 & 55.921 & 62.573 & 63.056 & 63.755 & 67.431 & 61.252 \\
Standard Deviation & 33.049 & 31.106 & 29.001 & 28.424 & 27.732 & 26.228 & 29.675 \\
Min & 0 & 0 & 0 & 0 & 0 & 0 & 0 \\
Max & 100 & 100 & 100 & 100 & 100 & 100 & 100 \\
\hline
\end{tabular}

Source: Own compilation from Province of Eastern Cape Education 
Descriptive Statistics: Table 1 provides descriptive statistics of the dropout and passes rates in grade 12 for the period from 2008 to 2013 . The pseudo panel data give a mean of $0.7 \%$ for the dropout rate, our dependent variable with a standard deviation of 1.8 , where these values fall between zero and $16.8 \%$. The mean value of $0.7 \%$ implies good performance as schools with zero dropout rates are an indicator that all learners who enrolled managed to write examinations. The dropout rate trend is consistent with the South African performance of $15.3 \%$ from 2008 to 2010 in National Income Dynamics Study (NIDS), although the author measured the cohort dropout rate (Branson et al., 2013). The Eastern Cape performed better than an American case, where the Mexican-American dropout rate was 35.3\%, the White non-Hispanic rate was $8.9 \%$ and the African-American rate was $13.5 \%$. The pass rate has a mean of $61.3 \%$ with a standard deviation of 29.7. Table 2indicates the percentages of dummies Dinaledi schools, gender, race and sector. There was 93.5 \%of non-Dinaledi schools, $95 \%$ of schools were public schools, gender was almost half-half and $79 \%$ of learners were Black.

Table 2: Distribution of some input variables

\begin{tabular}{lll}
\hline Variable & Frequency & Percent \\
\hline Non-Dinaledi & 12650 & 93.52 \\
Dinaledi & 877 & 6.48 \\
Females & 6771 & 50.03 \\
Males & 6752 & 49.97 \\
Blacks & 10690 & 79.00 \\
Non-Blacks & 2834 & 21.00 \\
Independent & 712 & 5.26 \\
Public & 12815 & 94.74 \\
\hline
\end{tabular}

Source: Own compilation from Province of Eastern Cape Education

The empirical model: The dependent variable in this study is grade 12-dropout rate by school, which is expected to have a negative association with explanatory variables. The explanatory variables are a range of learner, school and household characteristics drawn from repeated cross sections from 2008 to 2013 . The study attempts to estimate the following equation of the generic form:

$y_{i}=\alpha+\beta x_{i}+u_{i}$

' $y_{i}$ ' $\quad$ Refers to grade 12 dropout rate in school $i$ being a function of $k x 1$ vector, $\alpha$ captures the constant, $x$ refers to relevant explanatory variables, $\beta$ is the $k x 1$ vector of parameters which describe the transformation process of inputs to output and $u$ reflects measurement error in $\mathrm{x}$ and unobserved aspects of explanatory variables on output. The dependent variable, dropout rates, is a percentage change between learner enrolment and learners who wrote examinations. In this study, the event dropout rate is measured for the period 2008 to 2013, which is a proportion of learners who dropout in a single year without completing grade 12. Explanatory variables are pass rate and dummies of whether a school is a Dinaledi or not, race is Black and non-Black, gender is female and male, school quintiles are quintile one to five schools and sector is independent and public schools.

Reduced form equations suffer endogeneity bias due to unobservable characteristics. The bias can be addressed by employing a two-prong approach: the parametric and non-parametric approaches. The panel data (available for this study) of the reduced form enables us to obtain unbiased estimates of the effects of explanatory variables on output (Boardman \& Murnane 1979). The study adopts a parametric technique from Verbeek (2007), pseudo panels, for the period 2008 to 2013 in the Eastern Cape grade 12 schools and estimates the following function:

$y_{i t}=\alpha_{i}+x_{i t}^{\prime} \beta+u_{i t}, t=1, \ldots, T \quad E\left[x_{i t} u_{i t}\right]=0$ for each $t$

' $x_{i t}$ ' is K-dimensional vector of explanatory variables, $\beta$ is the parameter vector of interest and $i$ is schools with grade 12 (Verbeek 2007). It is assumed that the data set is a series of independent cross sections (pseudo panels) meaning repeated observations on T observations. If all observations are aggregated to cohort level, like school level, we have:

$\bar{y}_{c i t}=\bar{x}_{c i t}^{\prime} \beta+\bar{\alpha}_{c i t}, \quad c=1, \ldots, C \quad t=1, \ldots, T$ 
' $c$ ' is cohort of schools, $\bar{y}_{c i t}$ is the average value of all observed $y_{i t}$ in cohort c in period t. Cohort is defined by Deaton as 'a group with fixed membership, meaning individuals who can be identified as they show up in the sample. The main challenge with (4) is unobservable $\bar{\alpha}_{c i t}$ which is likely correlated with $\bar{x}_{c i t}$ if $\alpha_{i}$ is correlated with $x_{i t}$. Therefore treating $\bar{\alpha}_{c t}$ as part of a random error term is likely to lead to an inconsistent estimation. So, the solution is to treat $\bar{\alpha}_{c t}$ as a fixed unknown parameter and assume that variation over time is ignored (Verbeek, 2007). However, the Hausman test and the Breusch-Pagan Langrangian multiplier (LM test) are performed to test for the best consistent estimator(Torres-Reyna, 2007).

A linear dynamic model is measured with error and therefore an Anderson \& Hsiao (1981) estimator and more efficient GMM estimator of Arellano \& Bond (1991) cannot be used for pseudo panels (Verbeek, 2007). This is because y at $\mathrm{t}-1$ for individuals or households is unobservable but observable in true panels. Deaton (1985) suggests the use of cohorts to estimate a fixed effect model from repeated cross sections and this approach is as efficient as an instrument variable approach. The averages within cohorts are treated as if they were observations within pseudo panels (Deaton, 1985). The study is extended with the semiparametric approach which utilizes the DiNardo- Fortin-Lemieux (DFL) decomposition to compare distributions of Dinaledi schools between females and males (Johnston \& DiNardo, 1997). It is called a semiparametric approach because, within the parametric density approach such as DFL decomposition, we use the non-parametric approach like a probit or logit model. Parametric approaches are useful for exploratory data analysis, estimate standardized distributions to account for different characteristics and needs no specification of functional form. The following equation is estimated:

$g^{t}(y)=\int \theta f_{t}(y \mid x) h(x \mid D=t) d x$ where $\theta=\operatorname{Pr}(D=t) / \operatorname{Pr}(\mathbb{D}=\mathrm{t} \mid \mathrm{x})$

${ }^{\prime} g^{t}(y)^{\prime}$ is the hypothetical distribution showing a full distribution of observed output for the characteristics of $\mathrm{x}, \operatorname{Pr}(D=t)$ is the unconditional probability in the overall sample that an observation belongs to group $\mathrm{t}$ (females or males), Pri( $(\mathbb{D}=\mathrm{t} \mid \mathrm{x}$ ) is the conditional probability that can be estimated by means of a discrete choice model or non-parametrically (Johnston \& DiNardo, 1997), $f_{t}(y \mid x) h(x \mid D=t)$ is the joint distribution of output and characteristics for the group $t$.

The literature on education functions recognizes convergence, complementarities and lack of empirical evidence on proximity on parametric and non-parametric approaches (Chakraborty et al., 2001). Comparing results between the two approaches brings stability to the production function estimates and strong policy formulation. The expected results should yield a negative relationship between the dropout rate and the Dinaledi program, as this would mean few learners are leaving schools if there is intervention by the department. The limitations of this study are those school inputs that are not controlled for which does not allow us to assess the specific role of the Dinaledi program, but to measure the effects of resources in general. The subsequent reference to the effects of the Dinaledi program should be understood in this sense. As robust check of the effects of the Dinaledi program on schooling outcomes, the dependent variable was changed from the dropout rate to pass rates. The sign of the estimates is expected to change from negative to positive because the intervention program is expected to influence pass rates positively.

\section{Results and Discussion}

In an attempt to answer the research question of what is the association of the Dinaledi Intervention program with schooling outcomes, specifically dropout rate, different models such as pooled OLS, random and fixed effects were estimated. After testing for the more consistent and efficient estimator using the Hausman and the LM test, the random effect was chosen (Torres-Reyna, 2007). The Hausman test gave $\chi^{2}=2.48$ and Prob $>$ chi $2=0.9625$ therefore the preferred model for dropout rates is the random effects. The LM test for consistency between the pooled OLS and the random effect resulted into the random effect being the chosen model; withchibar2(01) $=4.35$ and Prob $>$ chibar $2=0.0185$.the results of this study indicate that dropout rates are negatively associated with whether a school is a Dinaledi school or not at the 5\% significant level in pooled, random and fixed effect estimations (table 3). Considering the random effect regression as a consistent and efficient estimator, Dinaledi schools are less likely to increase dropout rate by $0.0994 \%$ with reference to non-Dinaledi schools. These results indicate a significant impact of the Dinaledi Intervention program on schooling outcomes as measured by grade 12 event dropout rates in the period 2008 to 2013. Pittman (1991) found that dropout rates are associated with student social relationships within the school 
environment (Pittman, 1991). McMillan and Reed (1994) found dependence on adult relationships in their conceptual model of factors influencing resilience of at-risk students (Mcmillan \& Reed, 1994). Analogous to these afore-mentioned researchers and looking at the resources and support provided to Dinaledi schools such as learning material to learners, training educators and laboratories, it would be beneficial to provide this intervention program to all schools.

When random effect functions of females and males were estimated, it revealed that they had the expected sign and females were significant at $10 \%$ while males were insignificant (table 3 ). This implies that females of Dinaledi schools have a significant influence on grade 12 dropout rates in relation to females of nonDinaledi schools. This gender issue is further discussed below. Pass rates are negative and significant at 1\% significant level in all specifications. This means that an increase in the school's grade 12 pass rate would decrease the drop out in the school. To get more nuanced results, dropout rates were replaced with pass rates to represent schooling outcomes (table 4). The Hausman test indicated the fixed effect estimator as the more efficient and consistent estimator with a large $\chi^{2}=167.45$ and $\operatorname{Prob}>$ chi $2=0.0000$. The pseudo panel analysis indicates a positive and significant association of the Dinaledi schools to pass rates, implying that they are more likely to influence performance by $9.8 \%$ with reference to non-Dinaledi schools. Interestingly, Dinaledi schools are significantly affected by both males and females by about $10 \%$ in relation to non-Dinaledi schools. The dropout rate significantly explains pass rates with the decrease in dropout rate would increase pass rates by around $3 \%$, ceteris paribus.

Another set of variables that are very robust across the mean are the control variables such as race, gender, sector and quintile (tables $3 \& 4$ ). In this study race was grouped into Blacks and non-Blacks with Blacks as the referent. Non-Blacks are less likely to drop out of school than Blacks, both among females and males. Males are less likely to drop out of school in grade 12 than females (the referent). This highlights the racial and gender inequality challenges that still exist in the province. Interestingly, public schools perform better than independent schools (the referent) with large magnitudes as represented by the sector in table 3 . This is surprising because independent schools follow a model close to private schooling, which is expected to influence schooling outcomes better than public schools. However, this outcome supports the intuition of adopting the Dinaledi model at all public schools than increasing the independence of schools. Schools in quintiles two to five are less likely to have learners dropping out than quintile one (the referent) schools. Females in quintile three to five schools show insignificant results with different signs, while males show significant and negative results in all quintiles in the dropout rate analysis. Similar results were found when pass rates were used as a dependent variable. The quintile category needs a brief explanation. Quintile one are the poorest schools and quintile five are the richest schools. Quintile one to three are declared as poor schools, provided with nutrition, and allowed non-payment of fees. These results therefore, provide for a powerful policy message that the intervention is working well in the Eastern Cape except for females in quintile three to five.

Table 3: Estimates of dropout rate: Dependent Variable: Dropout rate

\begin{tabular}{llllll}
\hline VARIABLES & pooled & random effect & fixed effect & Female (RE) & Male (RE) \\
\hline Dinaledi & $-0.101^{* *}$ & $-0.0994^{* *}$ & $-0.0952^{* *}$ & $-0.116^{*}$ & -0.0806 \\
& $(0.0425)$ & $(0.0429)$ & $(0.0436)$ & $(0.0619)$ & $(0.0626)$ \\
Pass rate & $-0.00690^{* * *}$ & $-0.00684^{* * *}$ & $-0.00682^{* * *}$ & $-0.00673^{* * *}$ & $-0.00668^{* * *}$ \\
& $(0.000426)$ & $(0.000427)$ & $(0.000428)$ & $(0.000587)$ & $(0.000626)$ \\
Race 2 & $-0.181^{* * *}$ & $-0.163^{* * *}$ & $-0.157^{* * *}$ & $-0.195^{* * *}$ & $-0.122^{* *}$ \\
& $(0.0333)$ & $(0.0355)$ & $(0.0363)$ & $(0.0502)$ & $(0.0525)$ \\
Gender 2 & $-0.0893^{* * *}$ & $-0.0933^{* * *}$ & $-0.0947^{* * *}$ & & \\
& $(0.0215)$ & $(0.0215)$ & $(0.0217)$ & & \\
Sector 2 & $-1.415^{* *}$ & $-1.456^{* *}$ & $-1.458^{* *}$ & $-1.884^{* *}$ & -0.570 \\
& $(0.695)$ & $(0.695)$ & $(0.695)$ & $(0.833)$ & $(1.229)$ \\
Quintile 2 & $-0.149^{* * *}$ & $-0.150^{* * *}$ & $-0.151^{* * *}$ & $-0.106^{* *}$ & $-0.196^{* * *}$ \\
\hline
\end{tabular}




\begin{tabular}{llllll}
\hline & $(0.0353)$ & $(0.0353)$ & $(0.0353)$ & $(0.0488)$ & $(0.0510)$ \\
Quintile 3 & $-0.148^{* * *}$ & $-0.152^{* * *}$ & $-0.152^{* * *}$ & -0.0466 & $-0.259^{* * *}$ \\
Quintile 4 & $(0.0334)$ & $(0.0337)$ & $(0.0337)$ & $(0.0467)$ & $(0.0487)$ \\
& $-0.169^{* * *}$ & $-0.165^{* * *}$ & $-0.163^{* * *}$ & 0.0306 & $-0.360^{* * *}$ \\
Quintile 5 & $(0.0392)$ & $(0.0393)$ & $(0.0394)$ & $(0.0543)$ & $(0.0570)$ \\
& $-0.159^{* * *}$ & $-0.163^{* * *}$ & $-0.165^{* * *}$ & -0.0256 & $-0.309^{* * *}$ \\
Constant & $(0.0394)$ & $(0.0397)$ & $(0.0398)$ & $(0.0548)$ & $(0.0580)$ \\
& $2.674^{* * *}$ & $2.686^{* * *}$ & $2.712^{* * *}$ & $2.954^{* * *}$ & 1.903 \\
Observations & $(0.696)$ & $(0.697)$ & $(0.696)$ & $(0.833)$ & $(1.229)$ \\
R-squared & 12,627 & 12,627 & 12,627 & 6,299 & 6,328 \\
\hline
\end{tabular}

Source: Own compilation from Province of Eastern Cape Education; Stata 13 software

Notes:

Standard errors in parentheses, FE stand for Fixed Effect

${ }^{* * *} \mathrm{p}<0.01,{ }^{* *} \mathrm{p}<0.05,{ }^{*} \mathrm{p}<0.1$

Referents are non-Dinaledi schools, Blacks, Females, Independent schools, quintile 1 schools

Table 4: Estimates of pass rate: Dependent Variable: Pass rate

\begin{tabular}{llllll}
\hline & pooled & Random & Fixed & Female (FE) & Male (FE) \\
\hline Dinaledi & $8.558^{* * *}$ & $8.558^{* * *}$ & $9.804^{* * *}$ & $10.14^{* * *}$ & $10.10^{* * *}$ \\
& $(0.876)$ & $(0.876)$ & $(0.896)$ & $(1.312)$ & $(1.243)$ \\
Dropout rate & $-2.958^{* * *}$ & $-2.958^{* * *}$ & $-2.898^{* * *}$ & $-3.053^{* * *}$ & $-2.660^{* * *}$ \\
& $(0.182)$ & $(0.182)$ & $(0.182)$ & $(0.266)$ & $(0.249)$ \\
Race 2 & $18.79^{* * *}$ & $18.79^{* * *}$ & $16.44^{* * *}$ & $14.90^{* * *}$ & $17.94^{* * *}$ \\
& $(0.670)$ & $(0.670)$ & $(0.734)$ & $(1.055)$ & $(1.022)$ \\
Gender 2 & $2.557^{* * *}$ & $2.557^{* * *}$ & $2.749^{* * *}$ & & \\
& $(0.444)$ & $(0.444)$ & $(0.446)$ & & \\
Sector 2 & $35.78^{* *}$ & $35.78^{* *}$ & $36.54^{* *}$ & $41.98^{* *}$ & 23.43 \\
& $(14.40)$ & $(14.40)$ & $(14.33)$ & $(17.74)$ & $(24.51)$ \\
Quintile 2 & $2.212^{* * *}$ & $2.212^{* * *}$ & $2.285^{* * *}$ & 0.993 & $3.622^{* * *}$ \\
& $(0.731)$ & $(0.731)$ & $(0.728)$ & $(1.040)$ & $(1.018)$ \\
Quintile 3 & $1.590^{* *}$ & $1.590^{* *}$ & $1.707^{* *}$ & -0.0412 & $3.496^{* * *}$ \\
& $(0.693)$ & $(0.693)$ & $(0.695)$ & $(0.994)$ & $(0.972)$ \\
Quintile 4 & $9.335^{* * *}$ & $9.335^{* * *}$ & $9.082^{* * *}$ & $6.966^{* * *}$ & $11.26^{* * *}$ \\
& $(0.808)$ & $(0.808)$ & $(0.808)$ & $(1.154)$ & $(1.133)$ \\
Quintile 5 & $21.81^{* * *}$ & $21.81^{* * *}$ & $21.40^{* * *}$ & $18.63^{* * *}$ & $24.26^{* * *}$ \\
& $(0.793)$ & $(0.793)$ & $(0.799)$ & $(1.143)$ & $(1.118)$ \\
Constant & 13.81 & 13.81 & 13.40 & 12.63 & 24.41 \\
& $(14.42)$ & $(14.42)$ & $(14.35)$ & $(17.76)$ & $(24.53)$ \\
Observations & 12,627 & 12,627 & 12,627 & 6,299 & 6,328 \\
R-squared & 0.279 & 0.279 & 0.207 & 0.177 & 0.236 \\
\hline
\end{tabular}

Source: Own compilation from Province of Eastern Cape Education; Stata 13 software

Notes:

Standard errors in parentheses, FE stand for Fixed Effect

*** $\mathrm{p}<0.01,{ }^{* *} \mathrm{p}<0.05,{ }^{*} \mathrm{p}<0.1$

Referents are non-Dinaledi schools, Blacks, Females, Independent schools, quintile 1 schools 
Figure 1: Non-parametric estimation- dropout out rates

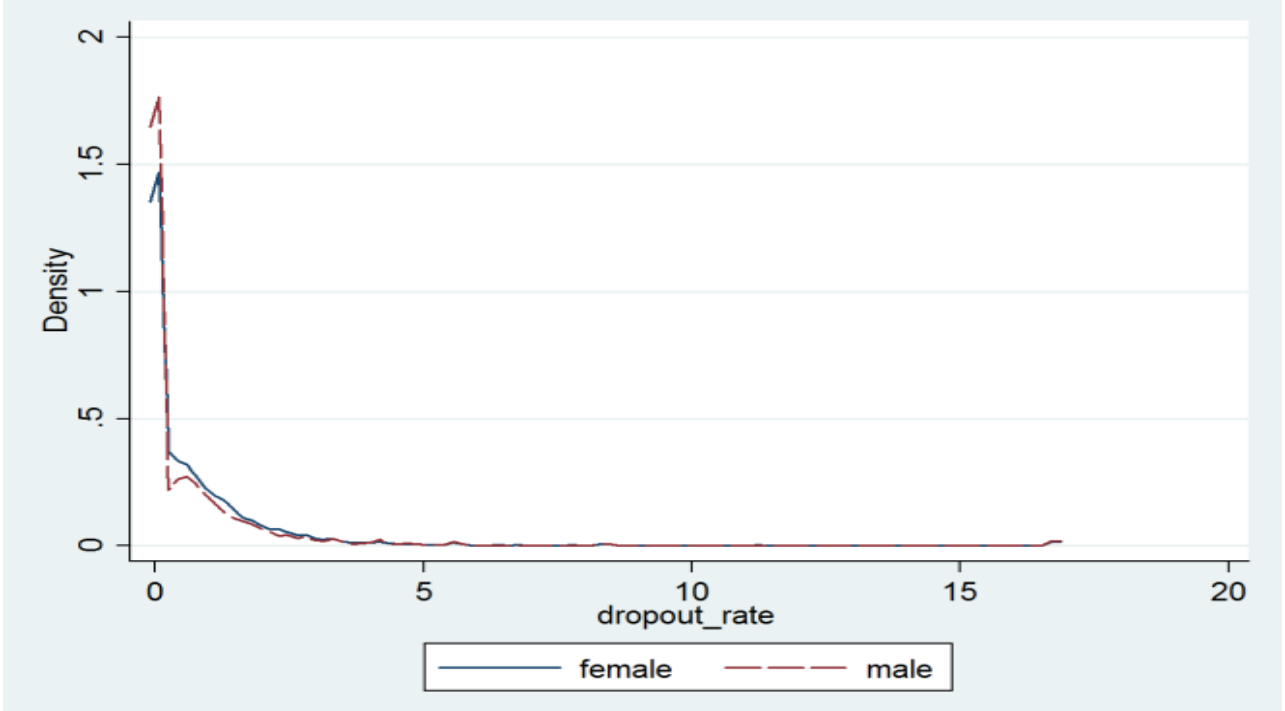

Source: Own compilation from Province of Eastern Cape Education; Stata 13 software

A non-parametric estimation was employed to estimate the density of dropout rates between males and females. A Gaussian kernel and default bandwidth was used for the estimations. In figure 1, it was found that females influence dropout rates more than males, which is consistent with the parametric estimation results. The non-parametric distribution approach shows the area between 0 and 5 for dropout rates as an area in which females differ from males. The distribution between males and females was further explored by employing DFL decomposition, where the distribution of males was made to look like those of females (figure 2). A counterfactual distribution of dropout rates was constructed using a probit model. It was found that if females had the characteristics of males, then the distribution would still look different in the same area. It turns out that the control variables used in the study do not explain the differences in the two distributions.

Figure 2: A non-parametric estimation DFL- dropout rate

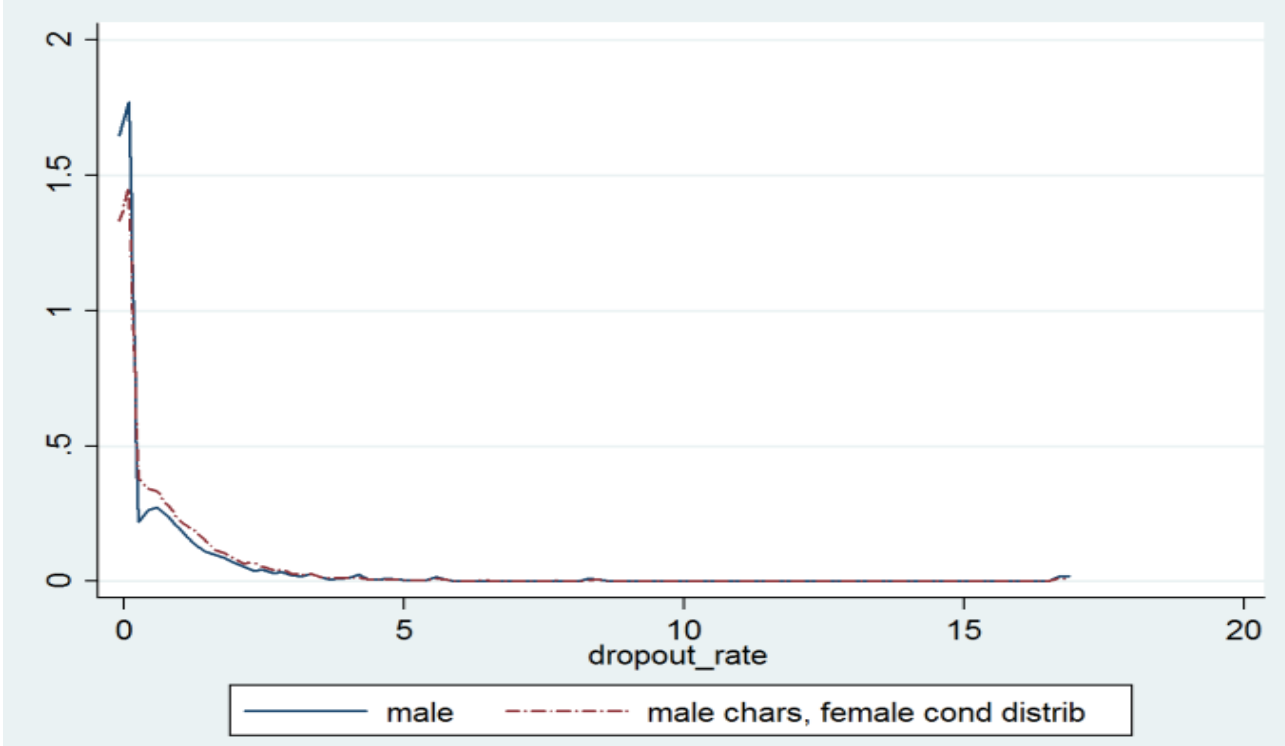

Source: Own compilation from Province of Eastern Cape Education; Stata 13 software 
Figure 3: A non-parametric estimation Dinaledi vs. dropout rate

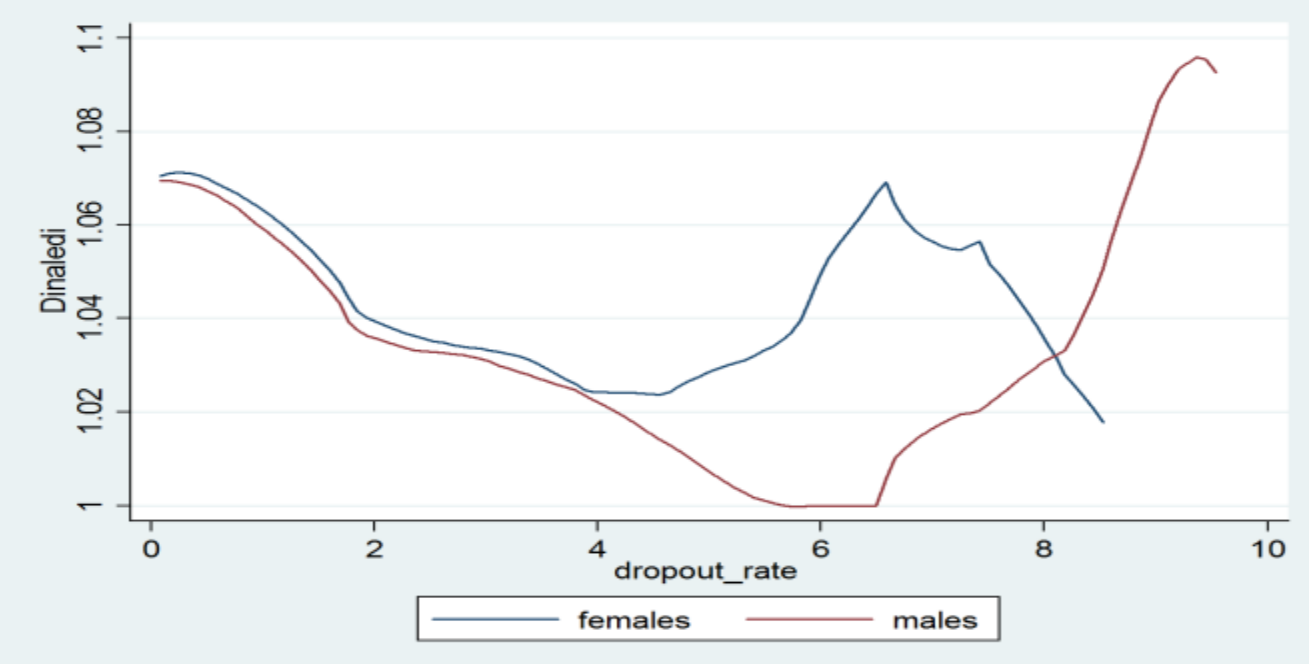

Source: Own compilation from Province of Eastern Cape Education; Stata 13 software

The analysis of the behavior of females and males was extended estimating a local linear regression for Dinaledi schools with Gaussian kernel and the default bandwidth (figure 3). The results suggested that in both females and males the provision of Dinaledi schools fluctuated with the dropout rate, beginning by a decrease then increases and then decreasing again. The decreasing part suggests that Dinaledi schools are less likely to increase dropout rates for either females or males, with females having a higher probability to dropout than males. Females divert quicker than males implying high response to the effect of Dinaledi schools on dropout rates. This suggests that treating schools to the Dinaledi intervention program influences schooling outcomes and females respond faster than males.

Figure 4: A non-parametric estimation- pass rates

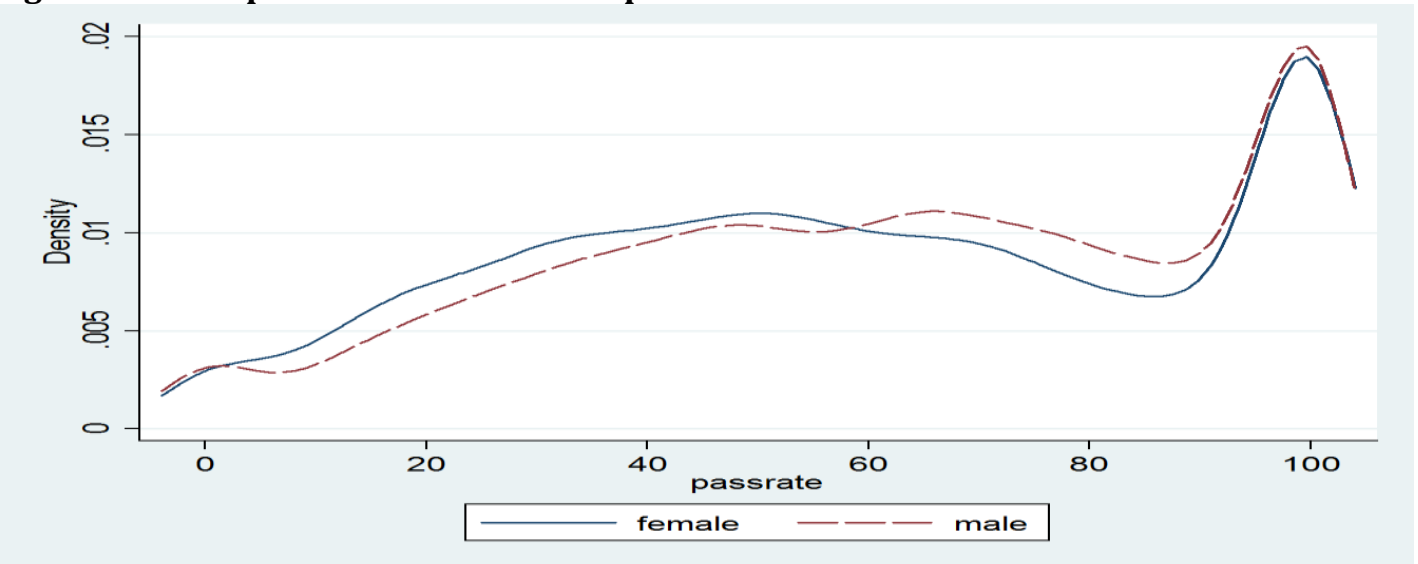

Source: Own compilation from Province of Eastern Cape Education; Stata 13 software

When a non-parametric estimation was further employed to estimate the density of pass rates between males and females, it was found that females influence pass rates more than males up to $60 \%$ of pass rates and gender roles changed thereafter (figure 4). The distribution between males and females was further explored by employing DFL decomposition, where the distribution of males was made to look like those of females (figure 5). A counterfactual distribution of pass rates was constructed using a probit model. It was found that if females had the characteristics of males, then the distribution would still look different in the same area. This endorsed the point that the control variables used in the study do not explain the differences in the two distributions. 
Figure 5: A non-parametric estimation DFL- pass rate

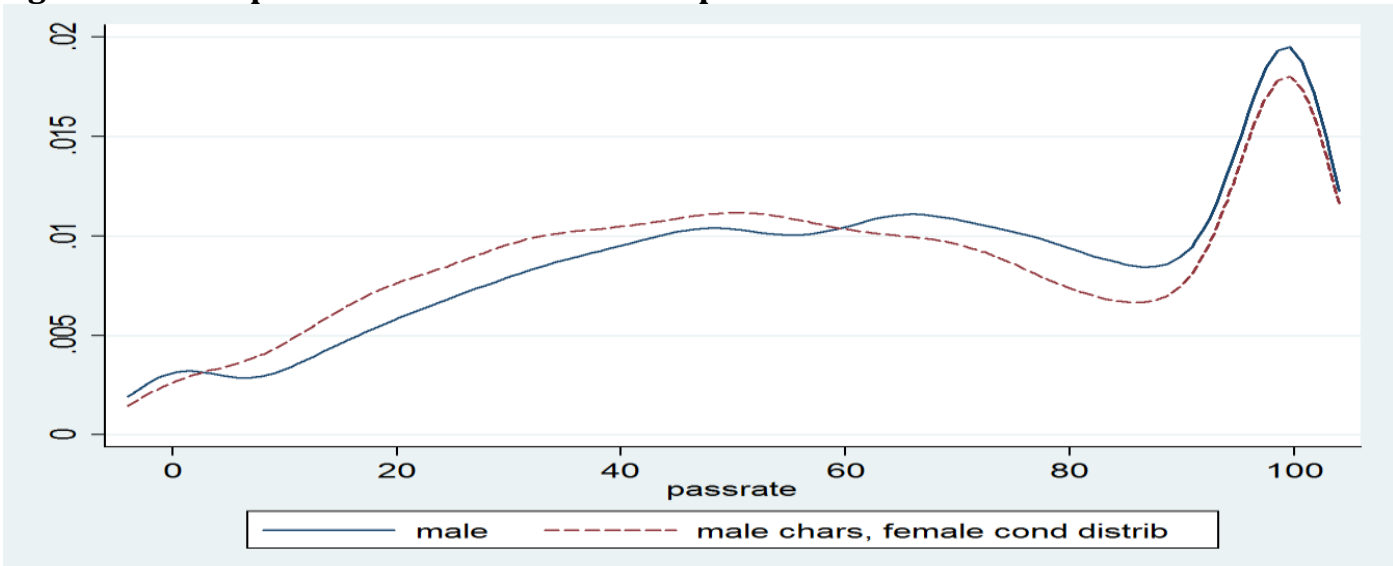

Source: Own compilation from Province of Eastern Cape Education; Stata 13 software

Figure 6: A non-parametric estimation Dinaledi vs. pass rate

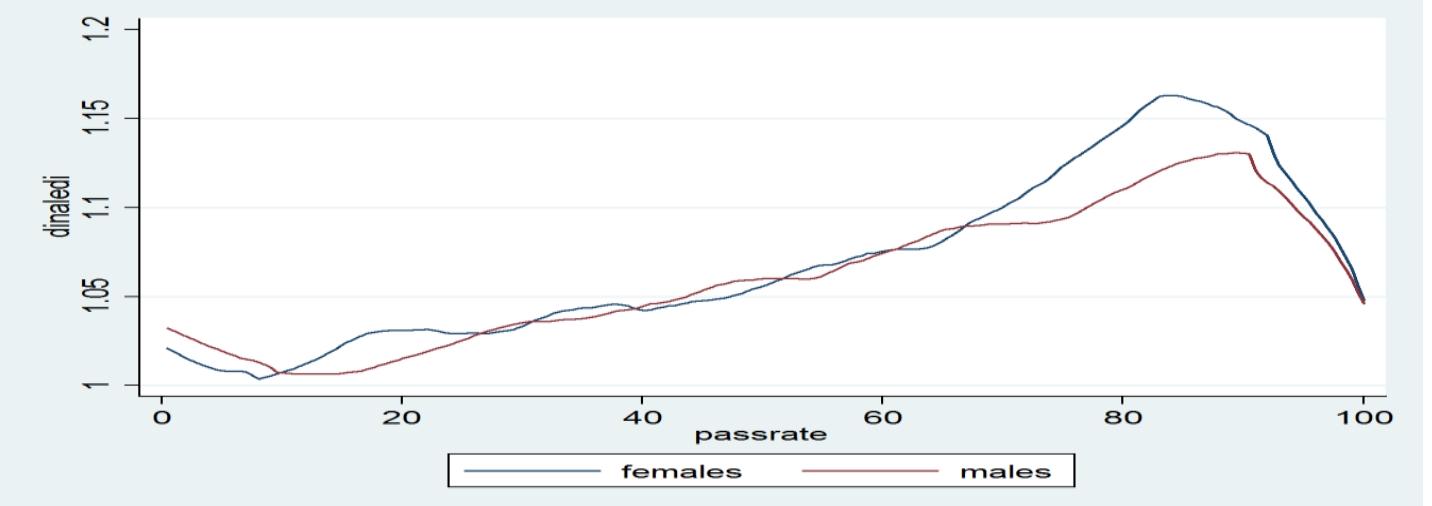

Source: Own compilation from Province of Eastern Cape Education; Stata 13 software

A local linear regression for Dinaledi schools with Gaussian kernel and the default bandwidth was estimated using pass rates as a dependent variable (figure 6). The results suggest that in both females and males, the provision of Dinaledi schools fluctuates with pass rates, but the case is indifferent and clearer after the $60^{\text {th }}$ percentile. This suggests that Dinaledi schools are more likely to increase pass rates for both females and males, with females having a higher probability to pass than males. This one again suggests that treating schools to the Dinaledi intervention program influences schooling outcomes and females are more affected than males.

\section{Conclusion and Recommendations}

The paper attempted to investigate the effects of the Dinaledi intervention program on schooling outcomes. The theory of education production functions was adopted and the intervention program was used as an input factor in the schooling system. Dropout and pass rates were used as a measure of schooling outcomes. Evidence from the pseudo panel analysis on the effects of the intervention program revealed a number of interesting results. Firstly, there was a significant association at $5 \%$ significant level of whether a school is a Dinaledi school or not on dropout rates. This means increasing the provision of Dinaledi intervention to schools can decrease the dropout rate. When pass rates were used as schooling outcomes, there was a strong positive relationship indicating that, an increase in the intervention can increase pass rates. Higher coefficients were found when pass rates were used as the dependent variable at $1 \%$ significant level. This indicates that pass rates represent better schooling outcomes than dropout rates. 
The equity issue was investigated by the inclusion of gender and race as control variables in the pseudo panel analysis. It was found out that Non-Blacks were less likely to drop out of school than Blacks even when females and males were estimated separately. Furthermore, the results showed that males were less likely to drop out of school in grade 12 than females. When the non-parametric estimation was employed to estimate the density of dropout rates between males and females, it was found that females influenced dropout rates more than males, even when the DFL decomposition was employed, where females had the characteristics of males. The analysis was extended between females and males by estimating a local linear regression for Dinaledi schools. This suggested that treating schools to the Dinaledi intervention program influences schooling outcomes and females respond quicker than males. Looking at the nature of resources and support provided to Dinaledi schools, it is recommended that schools can adopt the model to eradicate the legacy of inequality and improve schooling outcomes. Moreover, looking at the policy context of these results, it would be beneficial to adopt the Dinaledi model, as it is a useful tool to transform schools so that they become better learning institutions. Finally, it turns out that the schooling outcomes can be strongly explained by the Dinaledi intervention program with females and Blacks becoming more responsive to dropping out than their counterparts.

\section{References}

Behn, D. (2003). Why MeasurePerformance? Different Purposes Require Different Measures. Public administration review, 63(5), 586-606.

Bhorat, H. \& Oosthuizen, M. (2006). Determinants of Grade 12 Pass Rates in the Post-Apartheid South African Schooling System. Development Policy Research Unit, (October), 1-27.

Boardman, A., Davis, O. \& Sanday, P. (1977). A Simultaneous Equations Model of the Educational Process : The Coleman Data Revisited with an Emphasis on Achievement. Journal of Public Economics, 7, 23-49.

Boardman, A. \& Murnane, J. (1979). Using Panel Data to Improve Estimates of the Determinants of Educational Achievement. Sociology of education, 52(2), 113-121.

Borge, L. E. \& Naper, L. R. ( 2006). Efficiency Potential and Efficiency Variation in Norwegian Lower Secondary Schools. Mohr Siebeck GmbH \& Co. KG, 62(2), 221-249. Available at: http://openurl.ingenta.com/content/xref?genre=article\&issn $=0015218 \&$ volume $=62 \&$ issue $=2 \&$ spag e=221 [Accessed March 13, 2014].

Branson, N., Hofmeyr, C. \& Lam, D. (2013). Southern Africa labour and development research unit progress through school and the determinants of school dropout in South Africa, CAPE TOWN.

Chakraborty, K., Basudeband, B. \& Lewis, C. (2001). Measurement of Technical Efficiency in Public Education : A Stochastic Production Function Nonstochastic Approach. Southern economic journal, 67(4), 889905.

DBE. (2014). Education Statistics in South Africa. Government Printers, Pretoria.

Deaton, A. (1985). Panel data from time series of cross sections. Journal of Economietrics, 30, 109-126.

DIME. (2008). The Dinaledi program. , (Did), 1-3. Government Printers, Pretoria.

DoE. (2007). img-430121613-0001 provincial govt expenditure.pdf. , pp.1-10. Government Printers, Pretoria.

DoE. (2003). Improving access to free and quality basic education for all. Government Printers, Pretoria.

DoE. (2009). The Dinaledi schools project. Government Printers, Pretoria

DoE. (2011). S t r at e g i c p l a n 2007 - 2011. Government Printers, Pretoria.

Giménez, V., Prior, D. \& Thieme, C. (2006). Technical efficiency, managerial efficiency and objective-setting in the educational system: an international comparison. Journal of the Operational Research Society, 58(8), 996-1007. Available at: http://www.palgravejournals.com/doifinder/10.1057/palgrave.jors.2602213 [Accessed March 13, 2014].

Glewwe, P. (2002). Schools and Skills in Developing Countries: Education Policies and Socioeconomic Outcomes. Journal of Economic Literature, XL, 436-482.

Glewwe, P. \& Kremer, M. (2006). Schools, teachers and education outcomes in developing countries. Center for global development, 2(06).

Hanushek, E. A. (1989). Impact of differential expenditures on school performance. American Educatiion Research Association, 18(4), 45-51.

Hanushek, E. A. (1990). Developing Countries. In P. Glewwe, ed. Education Policy in Developing Countries.

Johnston, J. \& DiNardo, J. (1997). Econometric Methods 4th ed., McGraw-Hill. 
Mancebon, M. J. \& Molinero, C. M. (2000). Performance in primary schools. The journal of the operational research society, 51(7), 843-854.

Mcmillan, J. H. \& Reed, D. F. (1994). At-Risk students and resiliency : Factors contributing success to academic success. The Clearing house, 67(3), 137-140.

Mutsalklisana, C. (2011). Essays in labour and development Economics.

Ncanywa, T. (2014). The state of the Eastern Cape schools in a period almost the second decade of democracy. ERSA Working Paper 486, (December).

OECD. (2008). Review of national policies for Education: Government Printers, Pretoria.

Ray, S. (1991). Resource-use efficiency in public schools: a study of Connecticut data. Management Science, 37(12), 1620-1628. Available at: http://pubsonline.informs.org/doi/abs/10.1287/mnsc.37.12.1620 [Accessed March 13, 2014].

Schwartz, E. A. \& Stiefel, L. (2004). Immigrants and the Distribution of Resources Within an Urban School District. Educational evaluation and policy analysis, 26(4), 303-327.

Thieme, C., Giménez, V. \& Prior, D. (2011). A comparative analysis of the efficiency of national education systems. Asia Pacific Education Review, 13(1), 1-15. Available at: http://link.springer.com/10.1007/s12564-011-9177-6 [Accessed March 13, 2014].

Torres-Reyna, O. (2007). Panel data analysis Fixed and Random effects using Stata (v.4.2). , (December), 1-40. Verbeek, M. (2007). Pseudo panels and repeated cross-sections. Springer, 1-19.

Pittman, R. B. (1991). Social factors, in enrollment vocational / technical courses, and High school dropout rates. The journal of educational research, 84(5), 288-295. 